\title{
Article \\ Counteractive Effects of Sugar and Strigolactone on Leaf Senescence of Rice in Darkness
}

\author{
Ikuo Takahashi ${ }^{1}$, Kai Jiang ${ }^{2}$ (D) and Tadao Asami ${ }^{1, *}$ \\ 1 Graduate School of Agricultural and Life Sciences, The University of Tokyo, Tokyo 113-8657, Japan; \\ takahashi.190@gmail.com \\ 2 SUSTech Academy for Advanced and Interdisciplinary Studies, Southern University of Science and \\ Technology, Shenzhen 518055, China; jiangk@sustech.edu.cn \\ * Correspondence: asami@g.ecc.u-tokyo.ac.jp; Tel.: +81-3-5841-5157
}

check for

updates

Citation: Takahashi, I.; Jiang, K.; Asami, T. Counteractive Effects of Sugar and Strigolactone on Leaf Senescence of Rice in Darkness.

Agronomy 2021, 11, 1044.

https: / / doi.org/10.3390/

agronomy11061044

Received: 5 April 2021

Accepted: 19 May 2021

Published: 23 May 2021

Publisher's Note: MDPI stays neutral with regard to jurisdictional claims in published maps and institutional affiliations.

Copyright: (c) 2021 by the authors. Licensee MDPI, Basel, Switzerland. This article is an open access article distributed under the terms and conditions of the Creative Commons Attribution (CC BY) license (https:// creativecommons.org/licenses/by/ $4.0 /)$.

\begin{abstract}
Plant hormones strigolactones (SLs) were recently reported to induce leaf senescence. It was reported that sugar suppresses SL-induced leaf senescence in the dark; however, the mechanism of the crosstalk between SLs and the sugar signal in leaf senescence remains elusive. To understand this mechanism, we studied the effects of glucose (Glc) on various senescence-related parameters in leaves of the rice. We found that sugars alleviated SL-induced leaf senescence under dark conditions, and the co-treatment with Glc suppressed SL-induced hydrogen peroxide generation and membrane deterioration. It also suppressed the expression levels of antioxidant enzyme genes upregulated by SL, suggesting that Glc alleviates SL-induced senescence by inhibiting the oxidative processes. SLs can adapt to nutrient deficiency, a major factor of leaf senescence; therefore, we suggest the possibility that Glc and SL monitor the nutrient status in plants to regulate leaf senescence.
\end{abstract}

Keywords: leaf senescence; plant hormone; rice; reactive oxygen species; strigolactone; sugar

\section{Introduction}

Leaf senescence is a major developmental stage of the leaf and is accompanied by multilevel alterations, from the organelle to organ and the organism level. Contrary to the perception of this term, this phenomenon is not a negative process and plays an important role in the growth and development of plants. For instance, leaf senescence contributes to metabolism and the relocation of plant components, including proteins, nucleic acids (DNA and RNA), lipids, and nitrogen, from the old leaves to the sink organs such as the young leaves and seeds. Various endogenous and exogenous factors control leaf senescence [1-3]. Unfavorable environmental conditions such as drought, salinity, extreme temperatures, pathogen attack, and soil nutrient limitation influence the senescence rate of leaves. Additionally, plant hormones control leaf senescence either positively or negatively [4,5]. Ethylene, jasmonates, and abscisic acid accelerate this process and, among these, ethylene is considered a key plant hormone in promoting leaf senescence [6,7]. Conversely, cytokinins delay leaf senescence [7,8].

Strigolactones (SLs) are plant hormones that were originally discovered as inhibitors of shoot branching $[9,10]$; however, they are now known to be involved in many other aspects of plant development as well, including root development, secondary stem growth, and other physiological processes [11-13]. Before the discovery of SL as a plant hormone, some SL-deficient and SL-insensitive mutants in rice, Arabidopsis, and petunia have been identified as mutants with delayed leaf senescence [14-17]. Yamada et al. [18] and Ueda and Kusaba [19] verified the regulatory role of SLs on leaf senescence and reported that the application of GR24, a synthetic SL analog, accelerated dark-induced chlorophyll loss in SL-deficient mutants of rice and Arabidopsis and promoted the transcription of senescence-associated genes (SAGs) in their leaves. Additionally, the SL-deficient mutants 
displayed delayed leaf senescence in dark compared with their respective wild type counterparts $[18,19]$. During natural senescence, the transcription levels of SL biosynthesis genes in Arabidopsis, such as MAX3, MAX4, and MAX1, were upregulated [19], indicating that SLs are important senescence-promoting elements. In Arabidopsis, SL-induced leaf senescence is mediated by both ethylene-dependent and independent signals [19]. In rice, studies showed that the promoting effects of GR24 on leaf senescence increase under phosphate deficiency, indicating that SLs modulate leaf senescence in response to the phosphate levels [18]. These findings imply that various factors are involved in the regulation of SLinduced leaf senescence. As described above, senescence-promoting elements associated with SLs have been studied, but the role of senescence-inhibiting elements associated with SLs in the acceleration in leaf senescence remains unclear.

Chlorophyll loss causes reductions in the photosynthetic rate and photosynthetic proteins [20], and, as a result, the leaves undergo carbohydrate starvation [21,22]. Under dark conditions, leaf senescence is rapidly induced [23,24], which is associated with the drastic reduction in their chlorophyll content. In addition, darkness upregulates the expression of some of the SAGs in the leaves [25-28] and sugar-starvation-induced genes [25,26]. Treatment with sugars such as glucose (Glc) or sucrose (Suc) downregulates the expression of dark-induced genes [29] and dark-induced senescence in Arabidopsis leaves [30]. Therefore, sugars are considered to regulate leaf senescence under dark conditions by serving as signal molecules and/or energy resources. These findings led us to speculate that sugars are effective in counteracting SL-induced leaf senescence in dark. Tian et al. [31] recently demonstrated that the application of Glc to detached leaves of bamboo alleviated the visible SL-induced senescence in dark. However, the mechanism of the crosstalk between SL and sugar signals in leaf senescence is unclear. To gain further insights into the interaction between SL and sugar, we examined the effect of exogenously applied Glc on various senescence-related parameters in detached rice leaves. Our findings indicated that sugar alleviates SL-induced senescence in rice leaves. Overall, we suggest that crosstalk should exist between SL and sugar signals, which control the SL-induced leaf senescence in the dark.

\section{Materials and Methods}

\subsection{Chemicals}

GR24 was synthesized using the method described by Mangnus et al. [32], producing four stereoisomers which were separated using silica gel column chromatography. Sugars were purchased from FUJIFILM Wako Pure Chemicals (Osaka, Japan) and TCI (Tokyo, Japan).

\subsection{Plant Materials and Growth Conditions}

We used the rice (Oryza sativa L. Shiokari) SL-biosynthesis mutant $d 10-1$ with disrupted carotenoid cleavage dioxygenase 8 gene mutant in our study [33]. The sterilized seeds were incubated in water under dark, $25^{\circ} \mathrm{C}$ conditions for 2 days. The germinated seeds were then transferred to a hydroponic culture medium [10] solidified with $0.6 \%(v / v)$ agar and grown under fluorescent white light $\left(100 \mu \mathrm{mol} \mathrm{m}^{-2} \mathrm{~s}^{-1}\right)$ with a $16 \mathrm{~h} \mathrm{light} / 8 \mathrm{~h}$ dark cycle at $25^{\circ} \mathrm{C}$ for 10 days. Leaf segments, $2 \mathrm{~cm}$ long, were cut from the middle of the third leaf and the subsequent assay was performed as described previously [34].

\subsection{Measurement of Chlorophyll Content}

The total chlorophyll content was determined according to the method described by Takahashi et al. [34]. Three biological repeats were performed.

\subsection{Gene Expression Analysis}

The transcript levels of SAGs and antioxidant enzyme genes were analyzed using a quantitative reverse transcription-polymerase chain reaction (qRT-PCR) system. The SAGs studied were Osl20, Osl85, and Osl295, and the antioxidant enzyme genes 
studied were as follows: superoxide dismutase (SOD) (cytCuZnSOD2), catalase (CAT) $(C A T B)$, ascorbate peroxidase (APX) (APX1), and glutathione reductase (GR) (GR1). Total RNA extraction, reverse transcription, and PCR were performed as described by Takahashi et al. [34]. The transcript levels were normalized to those of the reference gene $(U B Q)$ [35]. The SAG-specific primers used were as described previously [18], and the antioxidant enzyme genes-specific primers used were as follows: $C A T B\left(5^{\prime}-\right.$ GGCAAGATCGTTTTCTCCAG-3' and 5'-TGGTTTCAGGTTGAGACGTG-3'), GR1 (5'CGTCATGAAACTGGTGGTTGATTCA- ${ }^{\prime}{ }^{\prime}$ and $5^{\prime}$-ATACCCTGGATAATCTCTGGTGCATC$\left.3^{\prime}\right)$, APX1 (5'-CCAAGGGTTCTGACCACCTA- ${ }^{\prime}$ and $5^{\prime}$-CAAGGTCCCTCAAAACCAGA$\left.3^{\prime}\right)$, and $c y t C u Z n S O D 2$ (5'-ACAGCCAGATCCCCCTTACT-3' and 5'-TACGAGCGAACATG AACAGC- $\left.3^{\prime}\right)$. Each sample had three biological replicates, which each had two technical replicates.

\subsection{Detection of Hydrogen Peroxide $\left(\mathrm{H}_{2} \mathrm{O}_{2}\right)$}

To detect the accumulation of $\mathrm{H}_{2} \mathrm{O}_{2}$ in the leaf segments, we used the diaminobenzidine (DAB) staining method as described by Thordal-Christensen et al. [36] with modifications. The leaf segments were stained with $1 \mathrm{mg} / \mathrm{mL} \mathrm{DAB}$ solution under dark at $25{ }^{\circ} \mathrm{C}$ for $4 \mathrm{~h}$. They were then bleached by boiling in $95 \%(v / v)$ ethanol $75{ }^{\circ} \mathrm{C}$ for $10 \mathrm{~min}$. Subsequently, the leaf segments were destained by rinsing them in deionized water twice, and photographed. DAB staining was quantified using ImageJ software (https:/ /imagej.nih.gov/ij/ [Date accessed: 5 April 2021]). Five biological replicates were performed. This experiment was independently repeated three times.

\subsection{Measurement of Electrolyte Leakage}

The electrolyte leakage was measured according to the method described previously [34]. Three biological replicas of the experiment were performed.

\subsection{Statistical Analysis}

The data were analyzed using GraphPad Prism 8 software (GraphPad Software Inc., San Diego, CA) with Student's $t$-test and Tukey's multiple comparison method, and $p<0.05$ was deemed to indicate statistical significance.

\section{Results}

First, we examined whether Glc application affected SL-induced chlorophyll loss because leaf yellowing due to chlorophyll loss is one of the obvious indicators during leaf senescence. A previous study showed that the application of GR24 accelerated the dark-induced reduction in the chlorophyll content in the leaf of rice SL biosynthesis mutants including $d 10$ mutant, although application of GR24 had no significant effect on the chlorophyll content in the leaf of wild-type plants [18]. The leaf segments of $d 10$ mutant treated with GR24 showed a greater reduction in the chlorophyll content than the control leaf segments (Figure 1a,b), but the wild type showed no significant difference on the third day after the treatment (Figure 1a). This result is consistent with the result obtained by Yamada et al. [18]. Thus, we confirmed that SL affected leaf senescence in the rice SL-biosynthesis mutant and decided to use the $d 10$ mutant for our study.

Initially, $1 \%$ Glc was applied to the leaf segments, referring to the report by Tian et al. [31]. The time-course change in chlorophyll content in detached leaves treated with Glc is shown in Figure 1a. The control leaf segments exhibited a gradual decrease in their total chlorophyll content until the third day of the treatment, after which the content dropped to approximately one-third of the original amount on the fourth day. In contrast, the Glc-treated leaf segments exhibited a moderate decrease in their total chlorophyll content. On day 7 , around $25 \%$ of the chlorophyll was retained in the Glc-treated leaves, albeit a basal level in the control leaves, indicating that Glc attenuated the SL-accelerated chlorophyll loss. Significant mitigation of the SL-induced reduction on the third day after the treatment was possible with concentrations of Glc above $0.25 \%$ (Figure 1c). Since 
$1 \%$ Glc-treated leave segments retained an equivalent amount of total chlorophyll as the control leaves, we continued to use a concentration of $1 \%$ in the following experiments.

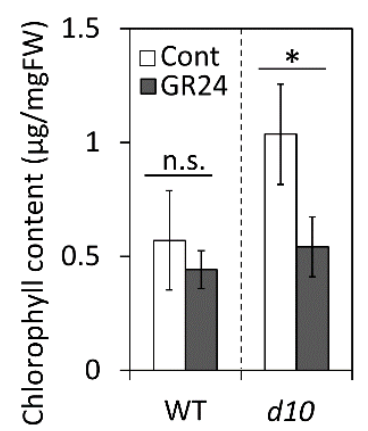

(a)

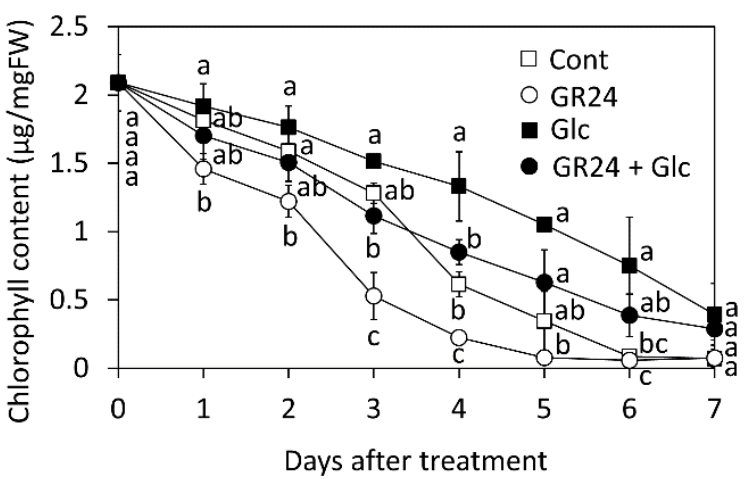

(b)

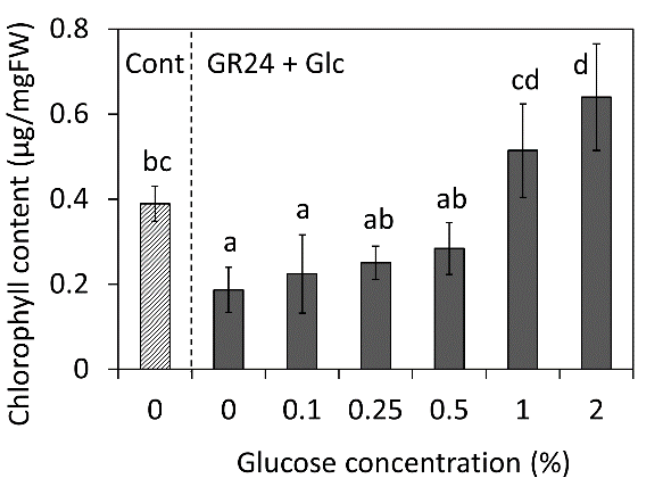

(c)

Figure 1. Effects of GR24 and glucose (Glc) on total chlorophyll content of leaf segments of rice d10 mutant. Leaf segments were treated with $1 \mu \mathrm{M}$ GR24 and $1 \%$ Glc at $25^{\circ} \mathrm{C}$ in dark. The control (Cont) was treated without GR24 and Glc. (a) Total chlorophyll content on the third day after GR24 treatment in the wild type (WT) and $d 10$ mutant. Values and bars show means $\pm \mathrm{SD}(n=3)$. Asterisk shows a significant difference $(p<0.05)$ in comparison with the control as determined by Student's $t$-test. n.s. represents no significance. (b) Time-courses of total chlorophyll content are shown. Values and bars show means $\pm \mathrm{SD}(n=3)$. Letters show a significant difference $(p<0.05)$ as determined by Tukey's HSD test at the same time point. (c) Total chlorophyll content on the third day after the treatment of different concentrations of Glc. Values and bars show means $\pm \operatorname{SD}(n=5)$. Letters show a significant difference $(p<0.05)$ as determined by Tukey's HSD test.

Application of fructose (Fru) and Suc also attenuated the GR24-induced chlorophyll loss in leaf segments, indicating that the counteractive effect of sugars on SL-induced senescence is not Glc-specific (Figure 2a). In contrast, the sugar alcohol mannitol (Mtl) had no inhibitory effect on GR24-induced reduction of chlorophyll. Similarly, leaves treated with 3-O-methyl glucose (3-OMG) showed a rapid reduction in the chlorophyll content, comparable to that of the control (Figure 2b). 3-OMG is a non-metabolizable analog of Glc, which is taken up by the plant cells but is not phosphorylated by hexokinase [37], thus indicating that metabolizable sugars can suppress SL-induced senescence in dark.

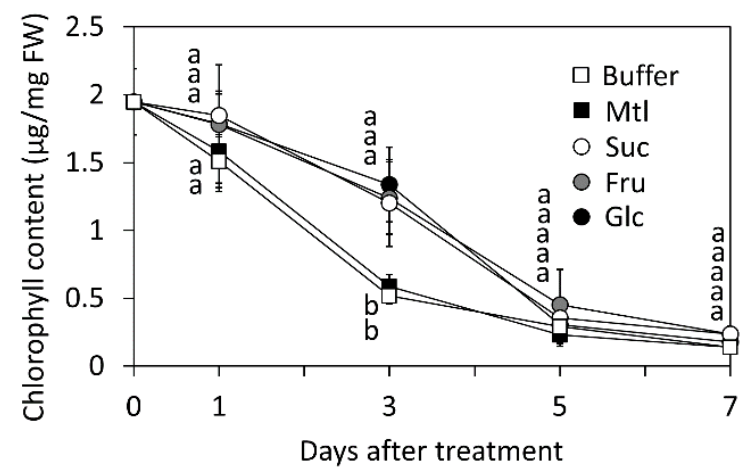

(a)

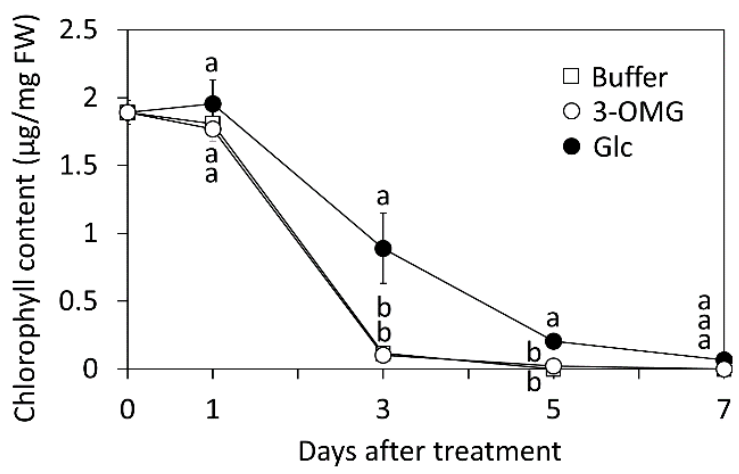

(b)

Figure 2. Effects of sugars on GR24-induced reduction in chlorophyll content in leaf segments of rice d10 mutant. Leaf segments were treated with $1 \mu \mathrm{M}$ GR2 4 and $1 \%$ sugars at $25{ }^{\circ} \mathrm{C}$ in dark. The control (Cont) was treated without sugars. (a) Total chlorophyll content in $1 \mu \mathrm{M}$ GR24-treated leaves with mannitol (Mtl), sucrose (Suc), fructose (Fru), and glucose (Glc) treatment. (b) Total chlorophyll content in GR24-treated leaves with 3-O-methyl glucose- (3-OMG) treatment. Values and bars show means $\pm \operatorname{SD}(n=3)$. Letters show a significant difference $(p<0.05)$ as determined by Tukey's HSD test at the same time point.

During senescence, the transcript levels of SAGs encoding multiple functions change to integrate the endogenous and exogenous cues [38], which plays an important role 
in controlling leaf senescence [39]. We measured the transcript levels of three SAGs (Osl20, Osl85, and Osl295) in the GR24- and Glc-treated leaf segments (Figure 3). Osl20, Osl85, and Osl295 encode $\alpha$-keto dehydrogenase, isocitrate lyase, and aspartic protease, respectively, which are drastically upregulated in the dark [38]. There is also a tendency for the expression of these three SAGs to be upregulated by GR24 treatment in leaf segments under dark conditions [18]. GR24 treatment drastically increased the SAG expressions on the second day after the treatment; the transcript levels of Osl20 and Osl85 gradually increased from the second to the fifth day after the treatment, whereas the transcript level of Osl295 decreased by the fifth day of the treatment. In contrast, the transcript levels of these genes in leaves co-treated with Glc were much lower, excluding the transcript level of Osl85 on the second day after the treatment. These data suggest that many processes other than chlorophyll loss contribute to SL-induced leaf senescence.
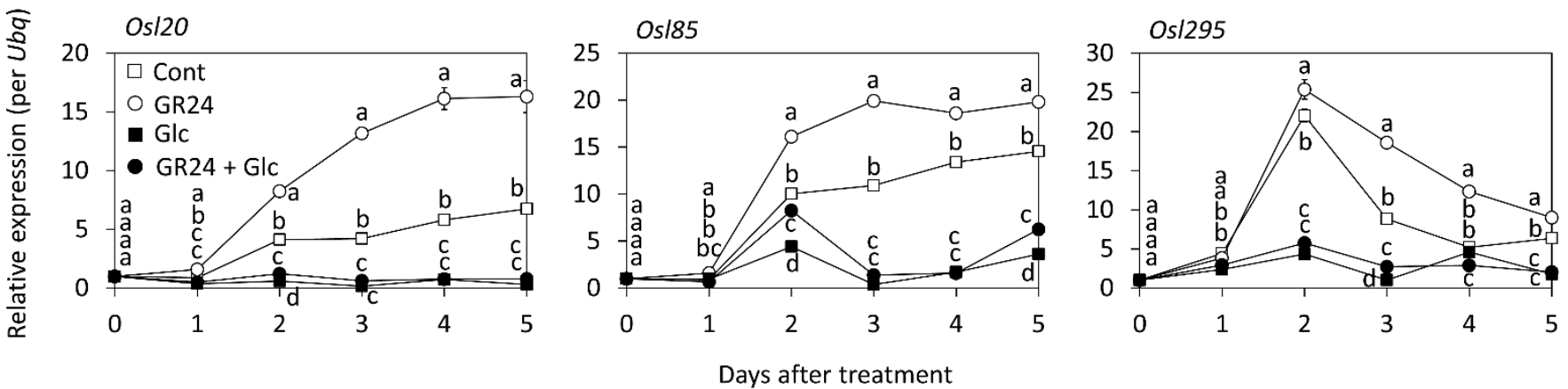

Figure 3. Effects of GR24 and glucose (Glc) on the transcript levels of senescence-associated genes. Rice leaf segments were treated with $1 \mu \mathrm{M}$ GR24 and $1 \%$ Glc in a 12-well plate at $25{ }^{\circ} \mathrm{C}$ in dark. The control (Cont) was treated without GR24 and Glc. Transcript accumulations of Osl20 (left), Osl85 (middle), and Osl295 (right) were measured by using qRT-PCR. Expression level at day 0 after the treatment in each gene was standardized. Values and bars represent means $\pm \operatorname{SD}(n=3)$. Each biological sample had two technical replicates. Letters show a significant difference $(p<0.05)$ as determined by Tukey's HSD test at the same time point.

One of the typical symptoms of leaf senescence is an increased production of reactive oxygen species (ROS) [40]. To detect the accumulation of $\mathrm{H}_{2} \mathrm{O}_{2}$, one of the precursors of ROS, we subjected the leaf segments to DAB staining 3 days after the treatment (Figure $4 a$ ). The leaf segments treated with GR24 displayed dark coloration, indicating significant accumulation of $\mathrm{H}_{2} \mathrm{O}_{2}$, whereas the leaf segments co-treated with GR24 and Glc exhibited comparatively weaker staining, similar to that observed in the leaf segments treatment with Glc and the control (Figure 4a,b).

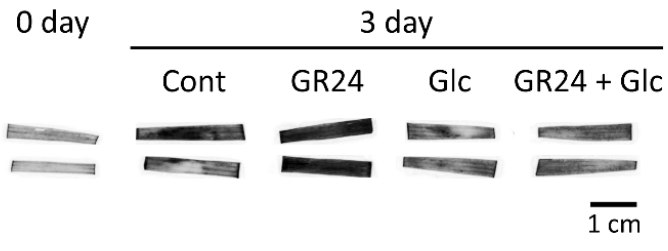

(a)

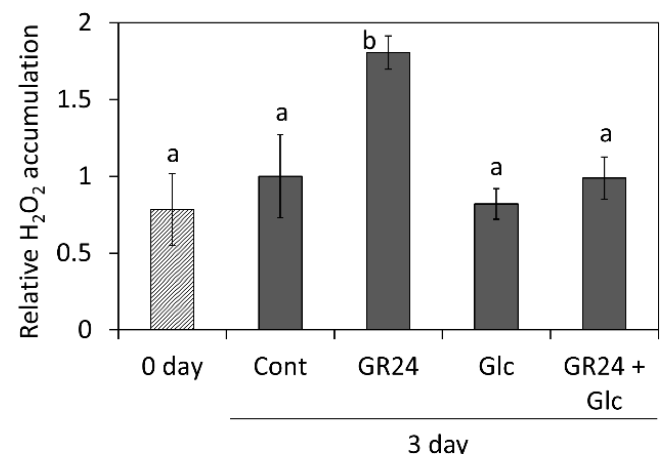

(b)

Figure 4. Diaminobenzidine staining to detect hydrogen peroxide $\left(\mathrm{H}_{2} \mathrm{O}_{2}\right)$. Leaf segments were treated with $1 \mu \mathrm{M}$ GR24 and $1 \%$ Glc at $25{ }^{\circ} \mathrm{C}$ in dark for 3 days. The control (Cont) was treated without GR24 and Glc. (a) Visualization of $\mathrm{H}_{2} \mathrm{O}_{2}$ accumulation in the leaf segments. Dark pigment indicates the presence of $\mathrm{H}_{2} \mathrm{O}_{2}$. The scale bar represents $1 \mathrm{~cm}$. (b) Relative $\mathrm{H}_{2} \mathrm{O}_{2}$ accumulation was quantified. Values and bars represent means $\pm \mathrm{SD}$ of five biological replicates. Letters indicate a significant difference $p<0.05$ ) as determined by Tukey's HSD test. 
In the present study, we measured the leaked electrolyte every second day (Figure 5). Co-treatment with Glc effectively inhibited the GR24-promoted electrolyte leakage as it induced a lower amount of electrolyte leakage in comparison with the GR24-treated leaf segments on the third day after the treatment (Figure 5).

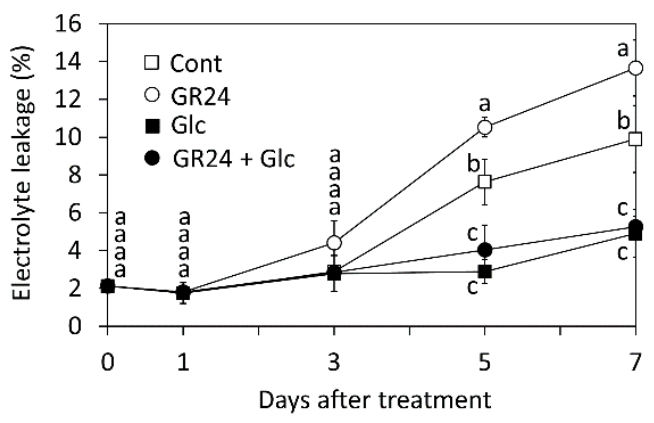

Figure 5. Effects of GR24 and glucose (Glc) on electrolyte leakage from rice leaf segments. Leaf segments were treated with $1 \mu \mathrm{M}$ GR2 4 and $1 \%$ Glc at $25^{\circ} \mathrm{C}$ in dark. The control (Cont) was treated without GR24 and Glc. Values and bars show means $\pm \mathrm{SD}(n=3)$. Letters show a significant difference $(p<0.05)$ as determined by Tukey's HSD test at the same time point.

The activities of several antioxidant enzymes including SOD, CAT, APX, and GR prevent the accumulation of ROS during oxidative stress conditions, thereby protecting the cells from the oxidative damage caused by ROS [41]. We monitored the changes in the transcription levels of the antioxidant enzyme genes in GR24- and Glc-treated leaf segments on the third day after the treatment (Figure 6). The expressions of all the antioxidant enzyme genes studied were supposed to be downregulated by Glc treatment, but instead were found to be significantly increased because of their upregulation by GR24 (Figure 6).

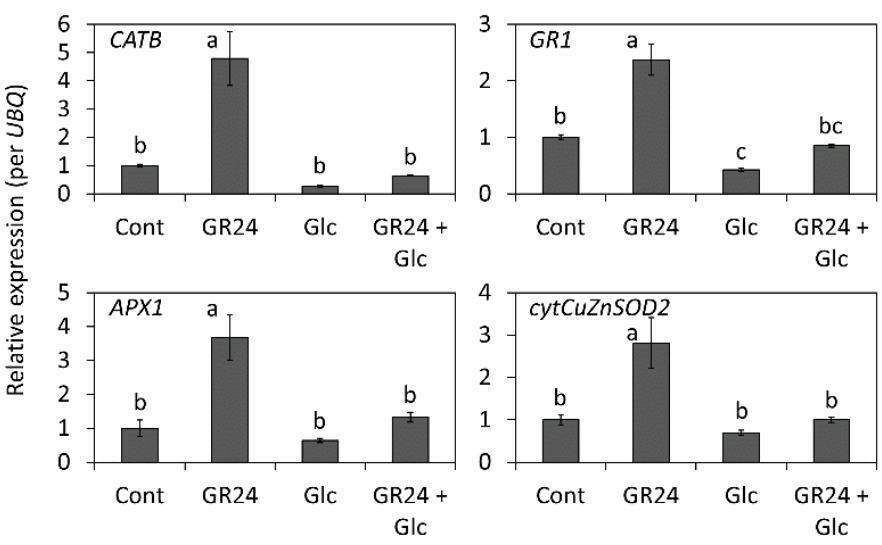

Figure 6. Effects of GR24 and glucose (Glc) on the expression of antioxidant enzyme genes in leaf segments on the third day after the treatment. Leaf segments were treated with $1 \mu \mathrm{M}$ GR24 and $1 \%$ Glc at $25^{\circ} \mathrm{C}$ in dark. The control was treated without GR24 and Glc. Transcript accumulation of each gene was measured using the qRT-PCR. The expression level of control in each gene was standardized. Values and bars represent means $\pm \operatorname{SD}(n=3)$. Each biological sample has two technical replicates. Letters show a significant difference $(p<0.05)$ as determined by Tukey's HSD test.

\section{Discussion}

SLs function as inducers of leaf senescence in dark; this dark-induced leaf senescence is associated with a drastic reduction in the total chlorophyll content, which causes a reduction in the photosynthesis rate and results in carbohydrate starvation in the leaves. Therefore, the carbohydrate content might be playing an important role in regulating leaf senescence induced by SL in the dark. In our previous study, we observed a drastic decrease in Suc levels in bamboo leaf segments in dark [31]; we also showed that application of 
soluble sugars such as Glc and Suc in combination with GR24 alleviated senescence in bamboo leaf segments, although the mechanism of this action was unclear. To clarify the regulatory mechanism of SL-induced leaf senescence in dark, we investigated the effect of sugars on SL-induced leaf senescence in the dark using rice as our model plant. Our results indicated that sugars suppress SL-induced leaf senescence by exerting a regulatory effect on ROS generation and antioxidant enzymes (Figure 7).

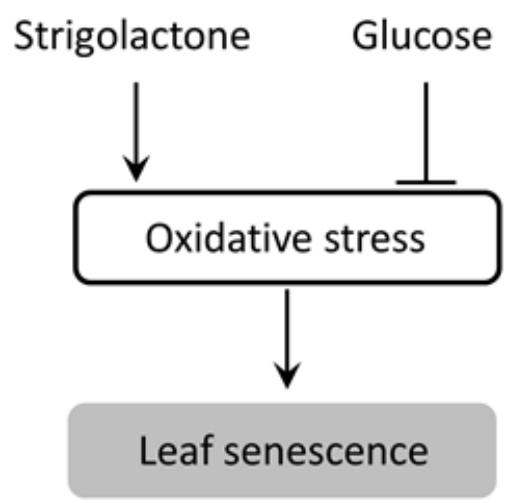

Figure 7. Proposed model of effect of SL and glucose on leaf senescence in darkness in this study.

The accumulation of ROS leads to oxidative stress, which causes an increase in the membrane lipid peroxidation and membrane permeability. As a result, there is a loss in the intracellular compartmentalization, leading to increased electrolyte leakage. Therefore, electrolyte leakage is widely used for quantifying leaf senescence. Yamada et al. [18] reported that GR24 application promoted electrolyte leakage from the leaf segments. The treatment with GR24 resulted in the accumulation of $\mathrm{H}_{2} \mathrm{O}_{2}$ (Figure $4 \mathrm{a}, \mathrm{b}$ ) and the enhancement of electrolyte leakage (Figure 5). In contrast, co-application with Glc inhibited both the accumulation of $\mathrm{H}_{2} \mathrm{O}_{2}$ and the increase in electrolytic leakage. An accumulation of ROS is accompanied by an accumulation of the antioxidant enzymes, which in turn detoxify the ROS and protect the plants from oxidative damage [41]. Our results confirmed that GR24 increases the expression of four antioxidant enzyme genes, whereas a co-treatment with Glc suppresses their expressions (Figure 6). This suggests that the expression level of some antioxidant enzyme genes oscillates with the senescence of the leaves, leading to changes in the activities of these enzymes. Overall, our findings indicate that Glc suppresses the SL-induced accumulation of ROS and sustains the oxidative condition. It has been reported that treatment with $\mathrm{H}_{2} \mathrm{O}_{2}$ decreases the chlorophyll and protein contents, and the progression toward senescence is followed by an increase in the $\mathrm{H}_{2} \mathrm{O}_{2}$ level in detached leaves of rice and maize [40,42-44]. Early senescence in a maize cultivar was reported to occur because of the induction of $\mathrm{H}_{2} \mathrm{O}_{2}$ formation and lipid peroxidation and the increase in the activity of different antioxidant enzymes at an early phase of senescence [45]. In Arabidopsis, the expressions of many SAGs were increased by the accumulation of ROS [46].

In abscisic-acid-treated rice leaf, following induction of $\mathrm{H}_{2} \mathrm{O}_{2}$ production at the initial stage of abscisic-acid-induced leaf senescence, lipid peroxidation and antioxidant enzymes such as SOD, CAT, APX, and GR were found to be increased [47]. However, SL-induced senescence has not been accounted for in the context of oxidative processes. Thus, on the basis of this study, we say that SL regulates the oxidant and antioxidant system in leaf senescence.

Several sugar species exhibit antioxidant capacity [48], and Mtl is reported to possess high ROS scavenging activity $[49,50]$. However, as Mtl treatment did not inhibit chlorophyll loss (Figure 2a), suppression of SL-induced senescence did not occur because of the antioxidant activities of the sugars.

The metabolized sugars, such as Glc, Fru, and Suc, attenuated the SL-induced reduction in chlorophyll content (Figure 2a), which is consistent with the findings of our 
previous study on detached bamboo leaves [31]. In contrast, Mtl and 3-OMG did not inhibit SL-induced reduction in chlorophyll content (Figure 2a,b). The metabolized sugars activate the sugar signal by phosphorylating themselves in the developing senescent stage [51]. The present findings suggest that sugar signals are involved in the suppression of SL-induced leaf senescence by creating $\mathrm{n}$ osmotic pressure. SLs are involved in sugar signaling in the development of Arabidopsis seedling [52]; the results of the present study also indicate the possible association of SLs with sugar signaling in the leaf senescence of rice.

Glc treatment suppressed the GR24-induced accumulation of $\mathrm{H}_{2} \mathrm{O}_{2}$, increased electrolyte leakage, and upregulated SAGs to the level of the control. However, Glc could neither suppress the GR24-induced reduction in chlorophyll content nor could delay its reduction (Figure 1b). Chlorophyll content significantly dropped on the first day after treatment in the GR24-treated leaves compared with the control leaves. In contrast, the accumulation of $\mathrm{H}_{2} \mathrm{O}_{2}$, electrolyte leakage, and SAGs significantly increased on the third day after the treatment. Thus, reduction in chlorophyll preceded the accumulation of $\mathrm{H}_{2} \mathrm{O}_{2}$, the increase in electrolyte leakage, and the upregulation of SAGs. Therefore, the sugar signal did not completely inhibit the reduction in chlorophyll in our study conditions.

Deficiencies in soil nutrients such as nitrogen and phosphate are the major environmental cues inducing leaf senescence. Under conditions of nitrogen and phosphate deficiency, nutrients are relocated as mobile forms from the old leaves to the reproductive and growing sink organs including young leaves and seeds to adapt to the ambient environment [53-55]. Nitrogen and phosphate deficiency enhances the production of SLs in some plant species including rice and sorghum [10,56,57]. In red clover and tomato, a deficiency in phosphate promotes SLs exudation $[58,59]$. SLs regulate leaf senescence by responding to the phosphate condition in rice [18]. Application of GR24 was reported to accelerate the senescence of rice $d 10$ mutant in phosphate-deficient conditions, suggesting that SLs promote nutrient allocation [60]. In leaves with sufficient amounts of sugars, senescence is not promoted as there is no nutrient allocation to the source organs. Sugars may monitor the sink-source condition and may negatively control the nutrient allocation by inhibiting the SL signal. Thus, there is a possibility that sugars and SLs function as sensors of the nutrient condition of the plant.

Thus, the present study showed that SLs and sugars interact with each other during the senescence process. From the viewpoint of agriculture, premature senescence results in reductions in the grain quality and crop yield [61]. Leaf senescence can be delayed by prolonging the duration of carbon supply to the grain, thereby leading to an increase in the grain mass. In this study, we presented new approaches to control the vitality of the crop plants that can be used to develop new methods for increasing grain yield. To achieve this goal, further studies are needed to clarify the physiological relationship between SLs and sugar on leaf senescence at the whole plant level as they are involved with activating signals throughout the plant body.

Author Contributions: Conceptualization, I.T., K.J., and T.A.; validation, I.T. and T.A.; formal analysis, I.T.; investigation, I.T.; data curation, I.T.; writing—original draft preparation, I.T.; writingreview and editing, T.A.; visualization, I.T.; supervision, T.A.; project administration, T.A.; funding acquisition, T.A. All authors have read and agreed to the published version of the manuscript.

Funding: This study was funded in part by a grant from the Core Research for Evolutional Science and Technology (CREST) Program of the Japan Science and Technology Agency (JST); the Japan International Cooperation Agency (JICA) and JST under a joint programme of Science and Technology Research Partnership for Sustainable Development (SATREPS); a JSPS Grant-in-Aid for Scientific Research (grant number 18H05266 to T.A.).

Institutional Review Board Statement: Not applicable.

Informed Consent Statement: Not applicable.

Data Availability Statement: Not applicable. 
Acknowledgments: The authors thank Junko Kyozuka (Tohoku University, Japan) for kindly providing the rice $d 10$ mutant.

Conflicts of Interest: The authors declare no conflict of interest.

\section{References}

1. Thomas, H.; Stoddart, J.L. Leaf Senescence. Annu. Rev. Plant Physiol. 1980, 31, 83-111. [CrossRef]

2. Brychkova, G.; Alikulov, Z.; Fluhr, R.; Sagi, M. A critical role for ureides in dark and senescence-induced purine remobilization is unmasked in the Atxdh1 Arabidopsis mutant. Plant J. 2008, 54, 496-509. [CrossRef]

3. Soltabayeva, A.; Srivastava, S.; Kurmanbayeva, A.; Bekturova, A.; Fluhr, R.; Sagi, M. Early Senescence in Older Leaves of Low Nitrate-Grown Atxdh1 Uncovers a Role for Purine Catabolism in N Supply. Plant Physiol. 2018, 178, 1027-1044. [CrossRef] [PubMed]

4. Dar, R.A.; Tahir, I.; Ahmad, S.S. Senescence: Regulation and Signalling. In Plant Signaling: Understanding the Molecular Crosstalk; Hakeem, K.R., Rehman, R.U.I., Ahmad, S.S., Eds.; Springer: New Delhi, India, 2014; pp. 257-266.

5. Soltabayeva, A.; Ongaltay, A.; Omondi, J.; Srivastava, S. Morphological, Physiological and Molecular Markers for Salt-Stressed Plants. Plants 2021, 10, 243. [CrossRef]

6. Zacarias, L.; Reid, M.S. Role of growth regulators in the senescence of Arabidopsis thaliana leaves. Physiol. Plant. 1990, 80, 549-554. [CrossRef]

7. Gan, S.; Amasino, R.M. Making Sense of Senescence (Molecular Genetic Regulation and Manipulation of Leaf Senescence). Plant Physiol. 1997, 113, 313-319. [CrossRef] [PubMed]

8. Badenoch-Jones, J.; Parker, C.; Letham, D.; Singh, S. Effect of cytokinins supplied via the xylem at multiples of endogenous concentrations on transpiration and senescence in derooted seedlings of oat and wheat. Plant Cell Environ. 1996, 19, 504-516. [CrossRef]

9. Gomez-Roldan, V.; Fermas, S.; Brewer, P.B.; Puech-Pagès, V.; Dun, E.A.; Pillot, J.-P.; Letisse, F.; Matusova, R.; Danoun, S.; Portais, J.-C.; et al. Strigolactone inhibition of shoot branching. Nat. Cell Biol. 2008, 455, 189-194. [CrossRef]

10. Umehara, M.; Hanada, A.; Yoshida, S.; Akiyama, K.; Arite, T.; Takeda-Kamiya, N.; Magome, H.; Kamiya, Y.; Shirasu, K.; Yoneyama, K.; et al. Inhibition of shoot branching by new terpenoid plant hormones. Nat. Cell Biol. 2008, 455, 195-200. [CrossRef]

11. Seto, Y.; Kameoka, H.; Yamaguchi, S.; Kyozuka, J. Recent Advances in Strigolactone Research: Chemical and Biological Aspects. Plant Cell Physiol. 2012, 53, 1843-1853. [CrossRef]

12. Ruyter-Spira, C.; Al-Babili, S.; van der Krol, S.; Bouwmeester, H. The biology of strigolactones. Trends Plant Sci. 2013, 18, 72-83. [CrossRef] [PubMed]

13. Al-Babili, S.; Bouwmeester, H.J. Strigolactones, a Novel Carotenoid-Derived Plant Hormone. Annu. Rev. Plant Biol. 2015, 66, 161-186. [CrossRef]

14. Woo, H.R.; Chung, K.M.; Park, J.-H.; Oh, S.A.; Ahn, T.; Hong, S.H.; Jang, S.K.; Gil Nam, H. ORE9, an F-Box Protein That Regulates Leaf Senescence in Arabidopsis. Plant Cell 2001, 13, 1779-1790. [CrossRef]

15. Snowden, K.C.; Simkin, A.J.; Janssen, B.J.; Templeton, K.R.; Loucas, H.M.; Simons, J.L.; Karunairetnam, S.; Gleave, A.P.; Clark, D.G.; Klee, H.J. The Decreased apical dominance1/Petunia hybrida CAROTENOID CLEAVAGE DIOXYGENASE8 Gene Affects Branch Production and Plays a Role in Leaf Senescence, Root Growth, and Flower Development. Plant Cell 2005, 17, 746-759. [CrossRef] [PubMed]

16. Yan, H.; Saika, H.; Maekawa, M.; Takamure, I.; Tsutsumi, N.; Kyozuka, J.; Nakazono, M. Rice tillering dwarf mutant dwarf3 has increased leaf longevity during darkness-induced senescence or hydrogen peroxide-induced cell death. Genes Genet. Syst. 2007, 82, 361-366. [CrossRef]

17. Hamiaux, C.; Drummond, R.S.; Janssen, B.J.; Ledger, S.E.; Cooney, J.; Newcomb, R.D.; Snowden, K.C. DAD2 Is an $\alpha / \beta$ Hydrolase Likely to Be Involved in the Perception of the Plant Branching Hormone, Strigolactone. Curr. Biol. 2012, 22, 2032-2036. [CrossRef] [PubMed]

18. Yamada, Y.; Furusawa, S.; Nagasaka, S.; Shimomura, K.; Yamaguchi, S.; Umehara, M. Strigolactone signaling regulates rice leaf senescence in response to a phosphate deficiency. Planta 2014, 240, 399-408. [CrossRef]

19. Ueda, H.; Kusaba, M. Strigolactone Regulates Leaf Senescence in Concert with Ethylene in Arabidopsis. Plant Physiol. 2015, 169, 138-147. [CrossRef]

20. Thomas, H. Enzymes of nitrogen mobilization in detached leaves of Lolium temulentum during senescence. Planta 1978, 142, 161-169. [CrossRef]

21. Stitt, M.; Wirtz, W.; Gerhardt, R.; Heldt, H.W.; Spencer, C.; Walker, D.; Foyer, C. A comparative study of metabolite levels in plant leaf material in the dark. Planta 1985, 166, 354-364. [CrossRef]

22. Brouquisse, R.; Gaudillère, J.-P.; Raymond, P. Induction of a Carbon-Starvation-Related Proteolysis in Whole Maize Plants Submitted to Light/Dark Cycles and to Extended Darkness1. Plant Physiol. 1998, 117, 1281-1291. [CrossRef]

23. Quirino, B.F.; Noh, Y.-S.; Himelblau, E.; Amasino, R.M. Molecular aspects of leaf senescence. Trends Plant Sci. 2000, 5, $278-282$. [CrossRef]

24. Brouwer, B.; Ziolkowska, A.; Bagard, M.; Keech, O.; Gardeström, P. The impact of light intensity on shade-induced leaf senescence. Plant Cell Environ. 2012, 35, 1084-1098. [CrossRef] 
25. Kleber-Janke, T.; Krupinska, K. Isolation of cDNA clones for genes showing enhanced expression in barley leaves during dark-induced senescence as well as during senescence under field conditions. Planta 1997, 203, 332-340. [CrossRef]

26. Weaver, L.M.; Gan, S.; Quirino, B.; Amasino, R.M. A comparison of the expression patterns of several senescence-associated genes in response to stress and hormone treatment. Plant Mol. Biol. 1998, 37, 455-469. [CrossRef]

27. Weaver, L.M.; Amasino, R.M. Senescence Is Induced in Individually Darkened Arabidopsis Leaves, but Inhibited in Whole Darkened Plants. Plant Physiol. 2001, 127, 876-886. [CrossRef]

28. van der Graaff, E.; Schwacke, R.; Schneider, A.; Desimone, M.; Flügge, U.-I.; Kunze, R. Transcription Analysis of Arabidopsis Membrane Transporters and Hormone Pathways during Developmental and Induced Leaf Senescence. Plant Physiol. 2006, 141, 776-792. [CrossRef]

29. Fujiki, Y.; Yoshikawa, Y.; Sato, T.; Inada, N.; Ito, M.; Nishida, I.; Watanabe, A. Dark-inducible genes from Arabidopsis thaliana are associated with leaf senescence and repressed by sugars. Physiol. Plant. 2001, 111, 345-352. [CrossRef]

30. Mair, A.; Pedrotti, L.; Wurzinger, B.; Anrather, D.; Simeunovic, A.; Weiste, C.; Valerio, C.; Dietrich, K.; Kirchler, T.; Nägele, T.; et al. SnRK1-triggered switch of bZIP63 dimerization mediates the low-energy response in plants. eLife 2015, 4, 05828. [CrossRef]

31. Tian, M.-Q.; Jiang, K.; Takahashi, I.; Li, G.-D. Strigolactone-induced senescence of a bamboo leaf in the dark is alleviated by exogenous sugar. J. Pestic. Sci. 2018, 43, 173-179. [CrossRef] [PubMed]

32. Mangnus, E.M.; Dommerholt, F.J.; de Jong, R.L.P.; Zwanenburg, B. Improved synthesis of strigol analog GR24 and evaluation of the biological activity of its diastereomers. J. Agric. Food Chem. 1992, 40, 1230-1235. [CrossRef]

33. Arite, T.; Iwata, H.; Ohshima, K.; Maekawa, M.; Nakajima, M.; Kojima, M.; Sakakibara, H.; Kyozuka, J. DWARF10, an RMS1/MAX4/DAD1 ortholog, controls lateral bud outgrowth in rice. Plant J. 2007, 51, 1019-1029. [CrossRef] [PubMed]

34. Takahashi, I.; Fukui, K.; Asami, T. On improving strigolactone mimics for induction of suicidal germination of the root parasitic plant Striga hermonthica. aBIOTECH 2021, 2, 1-13. [CrossRef]

35. Mashita, O.; Koishihara, H.; Fukui, K.; Nakamura, H.; Asami, T. Discovery and identification of 2-methoxy-1-naphthaldehyde as a novel strigolactone-signaling inhibitor. J. Pestic. Sci. 2016, 41, 71-78. [CrossRef]

36. Thordal-Christensen, H.; Zhang, Z.; Wei, Y.; Collinge, D.B. Subcellular localization of $\mathrm{H} 2 \mathrm{O} 2$ in plants. $\mathrm{H}_{2} \mathrm{O}_{2}$ accumulation in papillae and hypersensitive response during the barley-powdery mildew interaction. Plant J. 1997, 11, 1187-1194. [CrossRef]

37. Graham, I.A.; Denby, K.J.; Leaver, C.J. Carbon Catabolite Repression Regulates Glyoxylate Cycle Gene Expression in Cucumber. Plant Cell 1994, 6, 761-772. [CrossRef]

38. Lee, R.; Wang, C.; Huang, L.; Chen, S.G. Leaf senescence in rice plants: Cloning and characterization of senescence up-regulated genes. J. Exp. Bot. 2001, 52, 1117-1121. [CrossRef]

39. Lim, P.O.; Kim, H.J.; Gil Nam, H. Leaf Senescence. Annu. Rev. Plant Biol. 2007, 58, 115-136. [CrossRef]

40. Jajic, I.; Sarna, T.; Strzalka, K. Senescence, Stress, and Reactive Oxygen Species. Plants 2015, 4, 393-411. [CrossRef]

41. Gill, S.S.; Tuteja, N. Reactive oxygen species and antioxidant machinery in abiotic stress tolerance in crop plants. Plant Physiol. Biochem. 2010, 48, 909-930. [CrossRef]

42. Parida, R.K.; Kar, M.; Mishra, D. Enhancement of senescence in excised rice leaves by hydrogen peroxide. Can. J. Bot. 1978, 56, 2937-2941. [CrossRef]

43. Mondal, R.; Choudhuri, M. Role of Hydrogen Peroxide in Senescence of Excised Leaves of Rice and Maize. Biochem. und Physiol. der Pflanz. 1981, 176, 700-709. [CrossRef]

44. Lin, J.N.; Kao, C.H. Effect of oxidative stress caused by hydrogen peroxide on senescence of rice leaves. Bot. Bull. Acad. Sin. 1998, 39, 161-165.

45. Prochazkova, D.; Sairam, R.; Srivastava, G.; Singh, D. Oxidative stress and antioxidant activity as the basis of senescence in maize leaves. Plant Sci. 2001, 161, 765-771. [CrossRef]

46. Navabpour, S.; Morris, K.; Allen, R.; Harrison, E.; A-H-Mackerness, S.; Buchanan-Wollaston, V. Expression of senescence-enhanced genes in response to oxidative stress. J. Exp. Bot. 2003, 54, 2285-2292. [CrossRef]

47. Hung, K.T.; Kao, C.H. Hydrogen peroxide is necessary for abscisic acid-induced senescence of rice leaves. J. Plant Physiol. 2004, 161, 1347-1357. [CrossRef]

48. Bolouri-Moghaddam, M.R.; le Roy, K.; Xiang, L.; Rolland, F.; Ende, W.V.D. Sugar signalling and antioxidant network connections in plant cells. FEBS J. 2010, 277, 2022-2037. [CrossRef]

49. Smirnoff, N.; Cumbes, Q.J. Hydroxyl radical scavenging activity of compatible solutes. Phytochemistry 1989, 28, 1057-1060. [CrossRef]

50. Shen, B.; Jensen, R.G.; Bohnert, H.J. Mannitol Protects against Oxidation by Hydroxyl Radicals. Plant Physiol. 1997, 115, 527-532. [CrossRef]

51. Wingler, A. Transitioning to the Next Phase: The Role of Sugar Signaling throughout the Plant Life Cycle. Plant Physiol. 2018, 176, 1075-1084. [CrossRef]

52. Li, G.D.; Na Pan, L.; Jiang, K.; Takahashi, I.; Nakamura, H.; Xu, Y.W.; Asami, T.; Shen, R.F. Strigolactones are involved in sugar signaling to modulate early seedling development in Arabidopsis. Plant Biotechnol. 2016, 33, 87-97. [CrossRef]

53. Raghothama, K. Phosphate transport and signaling. Curr. Opin. Plant Biol. 2000, 3, 182-187. [CrossRef]

54. Smith, F.W.; Mudge, S.R.; Rae, A.L.; Glassop, D. Phosphate transport in plants. Plant Soil 2003, 248, 71-83. [CrossRef]

55. Masclaux-Daubresse, C.; Reisdorf-Cren, M.; Orsel, M. Leaf nitrogen remobilisation for plant development and grain filling. Plant Biol. 2008, 10, 23-36. [CrossRef] 
56. Yoneyama, K.; Xie, X.; Kusumoto, D.; Sekimoto, H.; Sugimoto, Y.; Takeuchi, Y.; Yoneyama, K. Nitrogen deficiency as well as phosphorus deficiency in sorghum promotes the production and exudation of 5-deoxystrigol, the host recognition signal for arbuscular mycorrhizal fungi and root parasites. Planta 2007, 227, 125-132. [CrossRef]

57. Jamil, M.; Charnikhova, T.; Cardoso, C.; Jamil, T.; Ueno, K.; Verstappen, F.; Asami, T.; Bouwmeester, H. Quantification of the relationship between strigolactones and Striga hermonthica infection in rice under varying levels of nitrogen and phosphorus. Weed Res. 2011, 51, 373-385. [CrossRef]

58. López-Ráez, J.A.; Charnikhova, T.; Gómez-Roldán, V.; Matusova, R.; Kohlen, W.; de Vos, R.; Verstappen, F.; Puech-Pages, V.; Bécard, G.; Mulder, P.; et al. Tomato strigolactones are derived from carotenoids and their biosynthesis is promoted by phosphate starvation. New Phytol. 2008, 178, 863-874. [CrossRef]

59. Yoneyama, K.; Xie, X.; Kim, H.I.; Kisugi, T.; Nomura, T.; Sekimoto, H.; Yokota, T.; Yoneyama, K. How do nitrogen and phosphorus deficiencies affect strigolactone production and exudation? Planta 2011, 235, 1197-1207. [CrossRef] [PubMed]

60. Umehara, M. Strigolactone, a key regulator of nutrient allocation in plants. Plant Biotechnol. 2011, 28, 429-437. [CrossRef]

61. Gregersen, P.L.; Culetic, A.; Boschian, L.; Krupinska, K. Plant senescence and crop productivity. Plant Mol. Biol. 2013, 82, 603-622. [CrossRef] 